\title{
The Impact of Worsening Heart Failure in the United States
}

Lauren B. Cooper, MD*, Adam D. DeVore, MD, G. Michael Felker, MD, MHS

\section{KEYWORDS}

- Worsening heart failure $\bullet$ Clinical trials $\bullet$ Outcomes $\bullet$ Medications

\section{KEY POINTS}

- In-hospital worsening heart failure is an increasingly important endpoint in trials of acute heart failure.

- In-hospital worsening heart failure is associated with increased short- and long-term mortality, rehospitalization, and health care costs.

- Renal dysfunction and cardiac dysfunction predict worsening heart failure in patients hospitalized with acute heart failure.

- A standardized definition of worsening heart failure should be established for use in future clinical trials.

\section{INTRODUCTION AND DEFINITIONS}

Heart failure is a common condition in the United States. More than 5 million Americans have heart failure, with more than 800,000 new cases diagnosed annually. ${ }^{1}$ This chronic condition is marked by episodes of acute decompensation, often requiring hospitalization. In the United States alone, there are greater than 1 million hospitalizations annually for acute heart failure. ${ }^{1}$ Unfortunately, patient outcomes remain poor with a 5 -year survival rate of approximately $50 \%$ and there is an urgent public health need to improve our understanding and treatment options for patients suffering with acute heart failure. ${ }^{1}$ Acute heart failure therapeutics remain largely homogenous and unchanged over the past 40 years in the United States. ${ }^{2,3}$

The term "worsening heart failure" has been used to indicate worsening of chronic heart failure, also termed "acute heart failure" or "acute decompensated heart failure." This acute worsening of chronic heart failure often results in adjustment of chronic therapy or requires in-patient hospitalization and is associated with worse prognosis. ${ }^{4,5}$ Worsening heart failure has also been used to

\footnotetext{
Disclosures: Dr L.B. Cooper reports receiving research support from Novartis. Dr A.D. DeVore reports receiving research support from Amgen, the American Heart Association, Novartis, Maquet, and Thoratec, and serving as a consultant for Maquet. Dr G.M. Felker reports receiving grant support from the National Heart, Lung, and Blood Institute, Novartis, Roche Diagnostics, Otsuka, and Amgen, and serving as a consulting for Trevena, Amgen, Novartis, Celladon, Sorbent, Bristol-Myers Squibb, Singlulex, St. Jude Medical, and Medtronic.

Funding Source: Dr L.B. Cooper was supported by grant T32HL069749-11A1 from the National Institutes of Health.

Disclaimer: The content is solely the responsibility of the authors and does not necessarily represent the official views of the National Heart, Lung, and Blood Institute, or the National Institutes of Health.

Duke Clinical Research Institute, PO Box 17969, Durham, NC 27715, USA

* Corresponding author.

E-mail address: lauren.b.cooper@duke.edu
} 
describe worsening of acute heart failure that occurs during a hospitalization for acute heart failure. For the purposes of this review, we focus on the latter condition, namely, in-hospital worsening heart failure.

In-hospital worsening heart failure represents a clinical scenario in which a patient hospitalized for treatment of acute heart failure experiences a worsening of their condition while in the hospital, requiring escalation of therapy. This can occur in patients who do not respond to initial therapy or in those who do respond to initial therapy but subsequently stop responding or worsen. Worsening heart failure can occur at any point throughout the hospitalization. ${ }^{6,7}$ There is a growing body of evidence that in-hospital worsening heart failure is also associated with a worse prognosis and signals an important change in the heart failure patient's clinical course (Fig. 1). These data suggest therapeutic strategies designed to reduce the incidence of in-hospital worsening heart failure could improve patient outcomes.

\section{ESTABLISHING A DEFINITION FOR WORSENING HEART FAILURE AS A CLINICAL TRIAL ENDPOINT}

Several clinical trials in acute heart failure have examined worsening heart failure as an endpoint. The first trial to define and examine worsening heart failure was published in 2004 and compared different doses of tezosentan, an endothelin receptor antagonist with vasodilating properties. ${ }^{8}$ This study included patients from centers in Europe, Israel, and the United States. Investigators examined both hemodynamic and clinical endpoints, including worsening heart failure, defined as "either failure to improve (persistent symptoms and signs of acute heart failure during the first $24 \mathrm{~h}$ of treatment) or recurrent symptoms and signs of acute heart failure, pulmonary edema, or cardiogenic shock after initial stabilization within 30 days after randomization, either of which required the initiation or increase of appropriate intravenous therapy or the implementation of mechanical circulatory or ventilatory support to treat the event." 8

The rationale for using worsening heart failure as an endpoint in acute heart failure trials was summarized in subsequent publications. ${ }^{9}$ Worsening heart failure during a hospitalization for acute heart failure was analogous to reinfarction after an episode of acute coronary syndrome-a failure of the initial treatment strategy. This endpoint was a departure from traditional acute heart failure studies that focused on acute symptoms - primarily dyspnea-or postdischarge outcomes. Neither acute symptoms nor postdischarge outcomes capture the inpatient clinical course, a critical time for heart failure patients. The purpose of worsening heart failure as an endpoint is to represent the inpatient course in a way that can be measured in a clinical trial. Furthermore, inhospital worsening heart failure is unique to episodes of acute heart failure. Recognizing the different physiology of acute and chronic heart failure underscores the need for different outcomes in clinical trials of these disease states. ${ }^{10}$

Despite the value of identifying worsening heart failure, there are also some challenges with using worsening heart failure as a clinical trial endpoint. Most notably, it may be difficult to ascertain whether escalation of care is due to true worsening of a patient's condition or due to initial undertreatment. This determination is particularly challenging for patients who are deemed

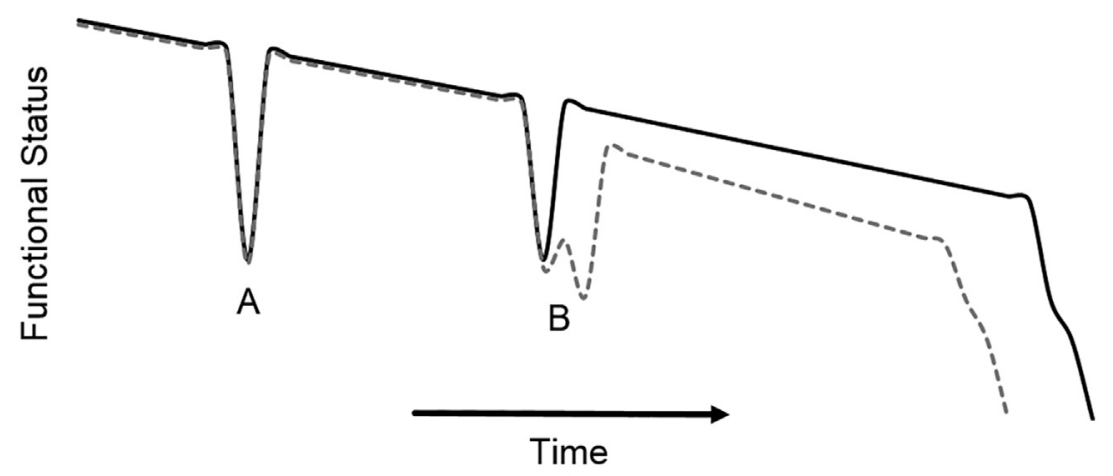

Fig. 1. Patient's clinical trajectory after an episode of in-hospital worsening heart failure (dotted gray line) compared with clinical trajectory without worsening heart failure (solid black line). The heart failure syndrome is characterized by acute changes in status typically requiring a hospitalization $(A)$. In-hospital worsening heart failure $(B$, dotted gray line) represents a more complicated and costly hospitalization associated with worse long-term outcomes. 
unresponsive to initial treatment and for patients classified as having worsening heart failure early in the hospital course.

\section{INITIAL DESCRIPTIONS OF THE INCIDENCE OF WORSENING HEART FAILURE AND ASSOCIATED OUTCOMES}

One of the first studies to examine the incidence of in-hospital worsening heart failure in patients admitted with acute heart failure was performed in a single-center, community hospital in Israel. ${ }^{9}$ Patients were considered to have in-hospital early worsening heart failure if, from 6 hours after admission through day 7 of admission, they had "unresolved or recurrent symptoms and signs of heart failure that required an increase in or institution of intravenous heart failure-specific therapy, or institution of mechanical ventilatory or circulatory support." They found that $29 \%$ of 337 patients experienced worsening heart failure, which was associated with increased mortality at 6 months (age-adjusted hazard ratio $[\mathrm{HR}], 3.3 ; 95 \% \mathrm{Cl}$, 1.7-6.3).

The incidence of worsening heart failure and associations with outcomes was investigated retrospectively in early studies of tezosentan using a slightly different definition of worsening heart failure, which captured clinical events occurring both during hospital admission and in the early postdischarge period. ${ }^{10}$ Specifically, worsening heart failure that occurred during the first 7 days of in-patient hospital admission was termed early worsening heart failure. In their study of 120 patients, 35\% experienced early worsening heart failure during the first 7 days of hospitalization, and $7 \%$ required readmission within 30 days of discharge. Most in-hospital worsening heart failure events were treated with an increased dose of diuretics (82\%). They found that patients with worsening heart failure were at higher risk of death at 6 months compared with patients without worsening heart failure (HR, $4.1 ; 95 \% \mathrm{Cl}, 1.3-13)$.

\section{WORSENING HEART FAILURE AS A TRIAL ENDPOINT}

Given the importance of identifying a meaningful endpoint for acute heart failure trials, and the proven association between in-hospital worsening heart failure and long-term clinical outcomes, worsening heart failure was incorporated into subsequent trials in acute heart failure, including VERITAS, ${ }^{11,12}$ PROTECT, ${ }^{13}$ ASCEND-HF, ${ }^{14,15}$ DOSE, ${ }^{16}$ REVIVE, ${ }^{17}$ RELAX-AHF, ${ }^{18,19}$ ROSEAHF, ${ }^{20}$ BLAST-AHF, ${ }^{21}$ and TRUE-AHF ${ }^{22}$ (Table 1). Each of these large clinical trials used different criteria to define worsening heart failure, but all with the same general framework of a worsening clinical condition. Most trials also specified that the worsening clinical condition required an escalation of therapy to be considered worsening heart failure. The REVIVE trials, however, used only the clinical condition and did not require escalation of therapy.

The other differences between the trial definitions are mostly related to the setting and timing of worsening heart failure. VERITAS, RELAXAHF, and BLAST defined worsening heart failure as occurring either during admission or early after discharge, whereas other trials defined worsening heart failure as occurring during index admission only. However, different trials focused on different timing of the occurrence of worsening heart failure. ASCEND-HF collected worsening heart failure events throughout the entire hospitalization, whereas DOSE and ROSE-AHF collected events from randomization through 72 hours, the REVIVE studies evaluated events that occurred after the first 24 hours and through day 5 of the hospitalization, and RELAX-AHF evaluated events that occurred through day 5 and also through day 14 . Despite these differences, all of the trials included similar requirements for what constituted escalation of care. These treatments included initiation or increase of intravenous therapies for heart failure (including diuretics, vasodilators, and inotropes), implementation of mechanical circulatory support or ventilatory support, or the initiation of ultrafiltration, hemofiltration, or hemodialysis.

Recent guidelines from the European Medicines Agency regarding studies of medications for the treatment of acute heart failure state that for worsening heart failure to be used as a clinical trial endpoint, clear and objective criteria must be prespecified to reduce variability and inconsistency. ${ }^{23}$ Although the Food and Drug Administration (FDA) has no such guidelines, they have raised similar issues for the worsening heart failure endpoint. ${ }^{24}$

\section{ASSOCIATION OF WORSENING HEART FAILURE WITH CLINICAL OUTCOMES}

From the clinical trial datasets detailed above, secondary analyses were performed to examine the association of worsening heart failure with clinical outcomes (Table 2). Worsening heart failure was found to be associated with worse in-hospital outcomes, including a longer length of stay, based on observations from the PROTECT pilot study and the VERITAS studies. ${ }^{25,26}$ Data from the PROTECT trial showed the association between worsening heart failure and an increased risk of all-cause mortality at 14 days and 30 days. ${ }^{27}$ The increased 


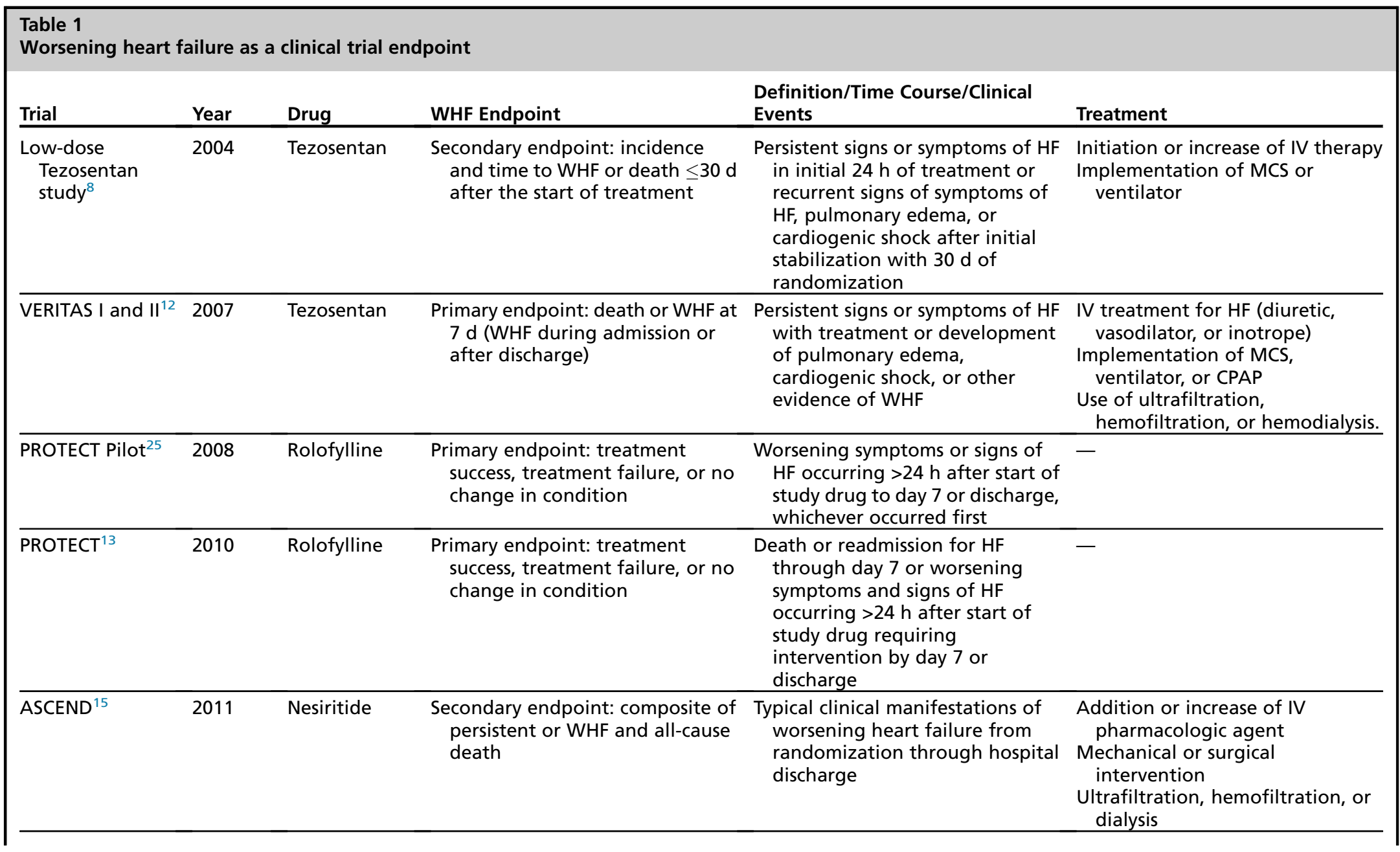




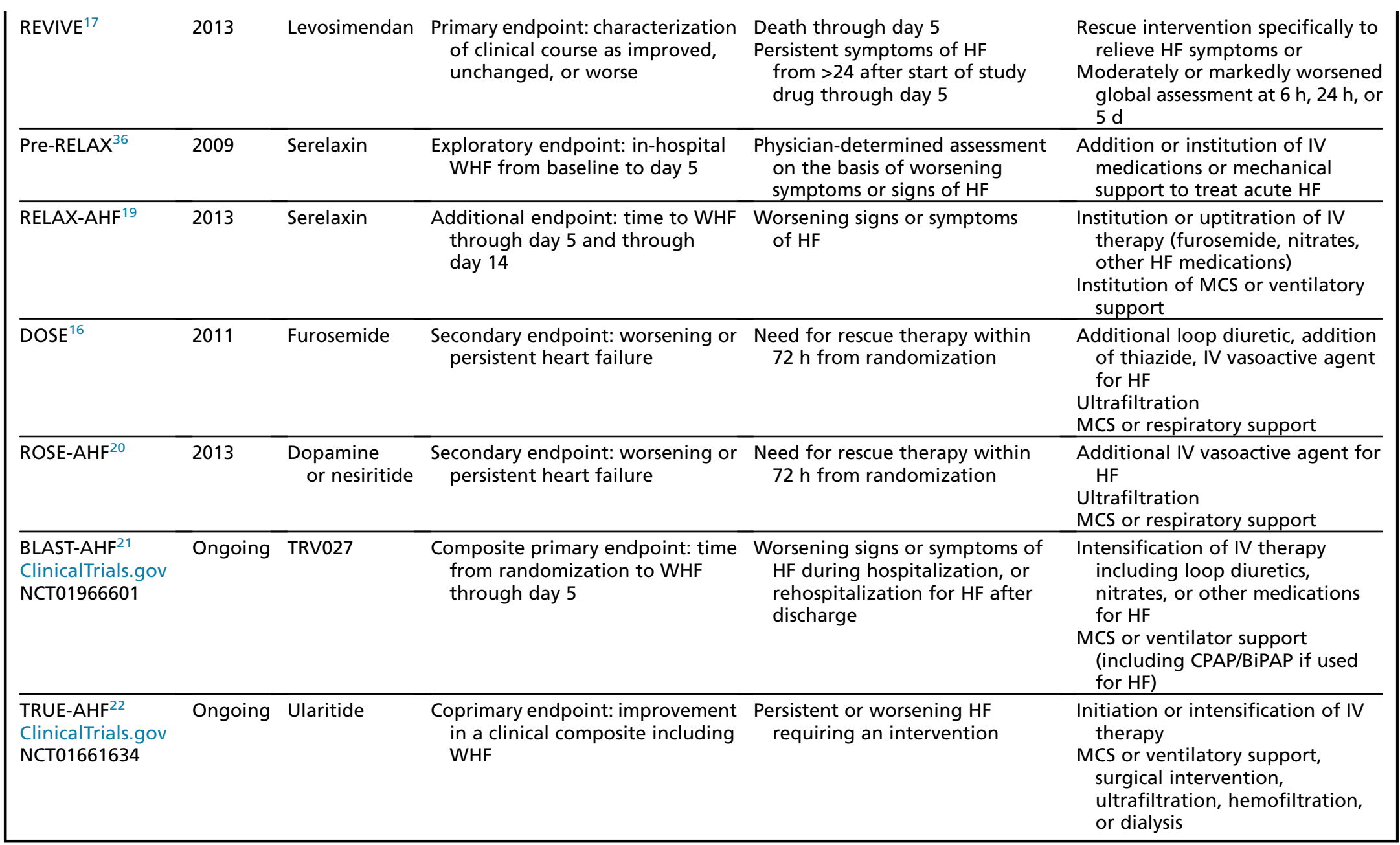

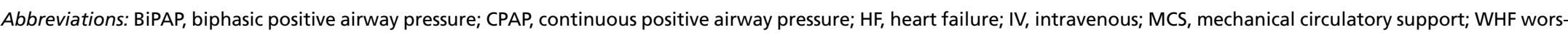
ening heart failure. 


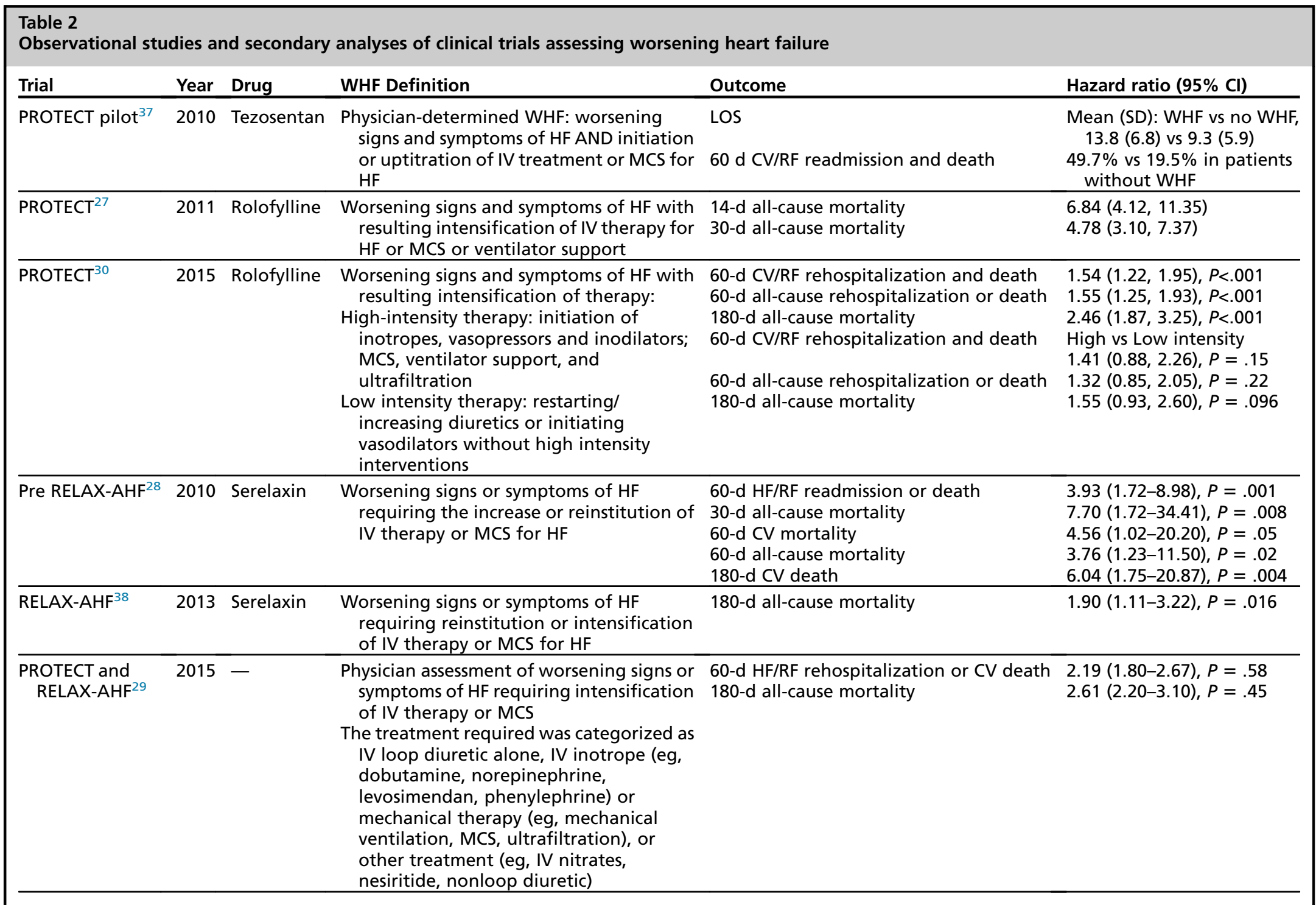




\begin{tabular}{|c|c|c|c|c|c|}
\hline VERITAS ${ }^{26}$ & 2014 & Tezosentan & $\begin{array}{l}\text { WHF could occur during the index } \\
\text { admission or after discharge } \\
\text { In-hospital: either (i) the development of } \\
\text { pulmonary edema, cardiogenic shock, or } \\
\text { other evidence of WHF or (ii) failure of } \\
\text { the patient's HF condition to improve } \\
\text { with treatment (treatment failure) } \\
\text { Required at least } 1 \text { of the following: (i) } \\
\text { initiation of new IV therapy, (ii) } \\
\text { reinstitution of prior IV therapy, (iii) } \\
\text { increase in current IV therapy for HF; (iv) } \\
\text { implementation of MCS or ventilatory } \\
\text { support, or (v) use of ultrafiltration, } \\
\text { hemofiltration, or hemodialysis }\end{array}$ & $\begin{array}{l}\text { LOS } \\
\text { 30-d HF rehospitalization or death } \\
90-\mathrm{d} \text { mortality }\end{array}$ & $\begin{array}{l}4.33(3.54-5.13), P<.001 \\
2.45(1.75-3.40), P<.001 \\
2.57(1.81-3.65), P<.001\end{array}$ \\
\hline ADHERE $^{31}$ & 2014 & Registry & $\begin{array}{l}\text { Any of the following criteria: initiated } \\
\text { inotropic medications or an IV } \\
\text { vasodilator }>12 \mathrm{~h} \text { after hospital } \\
\text { presentation, were transferred to the } \\
\text { ICU, or received advanced medical } \\
\text { therapy after the first inpatient day }\end{array}$ & $\begin{array}{l}\text { 30-d mortality } \\
1-y \text { mortality } \\
30-d \text { all-cause readmission } \\
1-y \text { all-cause readmission } \\
\text { 30-d HF readmission } \\
1-y \text { HF readmission } \\
\text { 30-d Medicare payments } \\
1-y \text { Medicare payments }\end{array}$ & $\begin{array}{l}\text { Hazard ratio }(99 \% \text { Cl) } \\
2.78(2.55-3.04), P<.001 \\
1.84(1.75-1.93), P<.001 \\
1.47(1.35-1.59), P<.001 \\
1.27(1.21-1.34), P<.001 \\
1.62(1.43-1.84), P<.001 \\
1.36(1.26-1.47), P<.001 \\
\text { Cost ratio }(99 \% C l) \\
1.70(1.57-1.84), P<.001 \\
1.43(1.37-1.49), P<.001\end{array}$ \\
\hline ASCEND $^{7}$ & 2015 & Nesiritide & $\begin{array}{l}\text { At least } 1 \text { sign, symptom, or radiologic } \\
\text { evidence of new, persistent, or } \\
\text { worsening acute HF requiring addition } \\
\text { of a new IV therapy (inotrope or } \\
\text { vasodilator) or mechanical support } \\
\text { during index hospitalization targeted } \\
\text { specifically at HF symptoms }\end{array}$ & $\begin{array}{l}\text { 30-d all-cause mortality or HF } \\
\text { hospitalization } \\
\text { 30-d all-cause mortality } \\
\text { 180-d all-cause mortality }\end{array}$ & $\begin{array}{l}8.43(6.70-10.60), P<.001 \\
16.56(12.58-21.79), P<.001 \\
5.05(4.23-6.03), P<.001\end{array}$ \\
\hline
\end{tabular}

(continued on next page) 


\begin{tabular}{|c|c|c|c|c|c|}
\hline Trial & Year & Drug & WHF Definition & Outcome & Hazard ratio $(95 \% \mathrm{Cl})$ \\
\hline ADHERE $^{6}$ & 2015 & Registry & $\begin{array}{l}\text { Any of the following criteria: use of IV } \\
\text { inotropes or vasodilators; mechanical } \\
\text { support including ventilator, dialysis, } \\
\text { IABP or LVAD; or an ICU stay during the } \\
\text { index hospitalization } \\
\text { Early WHF: occurred during day } 1 \text { of } \\
\text { hospitalization } \\
\text { Late WHF: occurred after day } 1 \text { of } \\
\text { hospitalization }\end{array}$ & $\begin{array}{l}\text { Early WHF vs late WHF } \\
30-d \text { mortality } \\
1-y \text { mortality } \\
\text { 30-d all-cause readmission } \\
1-y \text { all-cause readmission } \\
\text { 30-d HF readmission } \\
1-y \text { HF readmission } \\
\text { 30-d Medicare payments } \\
\text { 1-y Medicare payments }\end{array}$ & $\begin{array}{l}\text { Hazard ratio }(99 \% C l) \\
0.69(0.57-0.83), P<.001 \\
0.84(0.75-0.94), P<.001 \\
1.04(0.91-1.20), P=.44 \\
1.08(1.01-1.16), P=.003 \\
0.95(0.75-1.19), P=.54 \\
0.99(0.86-1.13), P=.81 \\
\text { Cost ratio }(99 \% C l) \\
1.09(0.94-1.28), P=.14 \\
1.26(1.16-1.37), P<.001\end{array}$ \\
\hline
\end{tabular}

Abbreviations: CV, cardiovascular; HF, heart failure; IABP, intraaortic balloon pump; ICU, intensive care unit; IV, intravenous; LOS, length of stay; LVAD, left ventricular assist device; MCS, mechanical circulatory support; RF, renal failure; WHF, worsening heart failure. 
risk of 30-day all-cause mortality was also observed in data from the Pre-RELAX trial. ${ }^{28}$ In addition, worsening heart failure was associated with increased all-cause mortality at 60 days, 90 days, and 180 days, and cardiovascular mortality at 60 days and 180 days. ${ }^{26,28-30} \mathrm{~A}$ recent analysis of ASCEND-HF confirmed increased risk of 30-day and 180-day mortality in patients with worsening heart failure compared with those without worsening heart failure. ${ }^{7}$

Extending the study of worsening heart failure out of the clinical trial space to provide realworld data from patients in the United States, worsening heart failure was recently examined in the Acute Decompensated Heart Failure National Registry (ADHERE). ${ }^{31}$ This analysis confirmed the findings of increased all-cause mortality at 30 days, and also found an increased mortality at 1 year. In addition to the mortality findings, there was an increased risk of all-cause and heart failure readmissions at 30 days and 1 year. Using Medicare claims data, the investigators also examined the financial implications of worsening heart failure. Because of increased readmissions for patients who experience worsening heart failure, it is not surprising that after discharge from the index hospitalization, postdischarge Medicare payments were shown to be greater at 30 days and 1 year for patients with worsening heart failure compared with those without worsening heart failure. ${ }^{31}$

In an effort to further examine the condition of worsening heart failure, several analyses examined timing of worsening heart failure. Two studies, one using data from ASCEND-HF and one using data from PROTECT, stratified worsening heart failure by whether it occurred before day 4 of hospitalization or after that time. ${ }^{7,30}$ There was no difference between timing of worsening heart failure and outcomes in these studies. A study using data from ADHERE categorized the timing of worsening heart failure differently. In this study, early in-hospital worsening heart failure was defined as occurring during hospital day 1 , and late worsening heart failure occurring after inpatient day $1 .{ }^{6}$ When defined by these time points, early worsening heart failure was associated with lower all-cause mortality but similar all-cause and heart failure rehospitalizations at 30 days and 1 year, compared with late in-hospital worsening heart failure.

Because worsening heart failure is defined by the need for escalation of therapy, 1 study delineated therapy as high intensity (initiation of inotropes, vasopressors, or inodilators; or initiation of mechanical support including circulatory support, ventilator support, or ultrafiltration) or low intensity (increasing diuretics or initiating vasodilators). ${ }^{30}$ There was no difference between the groups in the risk of death or hospitalization at 60 days or death at 180 days.

\section{TREATMENT OF WORSENING HEART FAILURE}

Although many trials have included worsening heart failure as an endpoint, most treatments have not been shown to be associated with decreased worsening heart failure. Compared with placebo, tezosentan was not associated with decreased incidence of worsening heart failure (odds ratio [OR], 0.99; 95\% Cl, 0.92-1.21), nor was rollofylline (OR, 1.13; $95 \% \mathrm{Cl}, 0.90$ 1.42). Similarly, in ASCEND-HF, the composite endpoint of worsening heart failure or death during index hospitalization was similar for the nesiritide group (4.2\%) and placebo group (4.8\%).

Two drugs have shown an improvement in worsening heart failure in adequately powered clinical trials-levosimendan and serelaxin. In the REVIVE trials, the placebo groups had more patients classified as worsening clinical course compared with the levosimendan groups. However, this study noted serious adverse events associated with the drug. Levosimendan has not been approved by the FDA for an indication in the acute decompensated heart failure patient population; however, this drug is being studied currently for use in patients with reduced left ventricular ejection fraction undergoing cardiac surgery (ClinicalTrials.gov NCT02025621). In the RELAX-AHF trial, treatment with serelaxin decreased worsening heart failure through day 5 ( $\mathrm{HR}, 0.3 ; 95 \% \mathrm{Cl}, 0.1-0.4)$ and day $14(\mathrm{HR}, 0.7$; $95 \% \mathrm{Cl}, 0.51-0.96) .{ }^{19}$ The worsening heart failure endpoint was exploratory and not prespecified. When serelaxin was evaluated by the FDA in 2014, the FDA report noted that the endpoint of worsening heart failure was not well-characterized in the RELAX-AHF trial. ${ }^{24} \mathrm{~A}$ larger trial of serelaxin is ongoing, with worsening heart failure as a prespecified secondary endpoint (ClinicalTrials.gov NCT NCT01870778).

\section{PREDICTION OF WORSENING HEART FAILURE}

The frequent occurrence of worsening heart failure in patients hospitalized with acute heart failure, and the association of worsening heart failure with poor outcomes including rehospitalization and death, has motivated the development of worsening heart failure as an important outcome in the care of patients with acute heart failure and highlighted the importance of prevention of worsening heart failure in these patients. Using clinical trials and registries, several groups have 
developed prediction models for the development of worsening heart failure (Table 3 ). Predictors of death, heart failure rehospitalization, or worsening heart failure at 7 days in PROTECT and validated in VERITAS include blood urea nitrogen, albumin, and cholesterol, as well as heart rate, systolic blood pressure, and respiratory rate, with blood urea nitrogen being the strongest predictor. Using patients from both PROTECT and RELAX-AHF, predictors of death or worsening heart failure through day 5 included blood urea nitrogen, hematocrit, respiratory rate, and systolic blood pressure. A risk model developed in ADHERE and validated in ASCEND found several variables that were associated independently with the development of in-hospital worsening heart failure, including age, heart rate, systolic blood pressure, left ventricular ejection fraction, and the laboratory values of brain natriuretic peptide, troponin, sodium, blood urea nitrogen, and creatinine. The strongest predictors were troponin and creatinine. Taken together, it seems that renal dysfunction, cardiac injury, and markers of decompensation all predict worsening heart failure.

\section{DEVELOPING THERAPEUTICS AND TREATMENT STRATEGIES THAT DECREASE WORSENING HEART FAILURE}

From the first use of worsening heart failure as an endpoint in 2004, there is now a robust body of evidence linking worsening heart failure with poor future outcomes. This endpoint may offer significant advantage over other symptom-based and clinical endpoints. ${ }^{32,33}$

Acute heart failure is recognized currently as a heterogeneous disorder characterized by symptoms, typically dyspnea, and findings of congestion and/or poor perfusion that clearly represent a deviation from the typical journey of a patient

\begin{tabular}{|c|c|c|c|c|c|}
\hline Trial & Year & Outcome & Predictors & C-Statistic & $\begin{array}{l}\text { External Validation } \\
\text { (C-statistic) } \\
\end{array}$ \\
\hline $\begin{array}{l}\text { PROTECT and } \\
\text { RELAX-AHF }{ }^{29}\end{array}$ & 2015 & $\begin{array}{l}\text { Death or WHF } \\
\text { through day } 5\end{array}$ & $\begin{array}{l}\text { Higher blood urea } \\
\text { nitrogen } \\
\text { Respiratory rate } \\
\text { Hematocrit } \\
\text { Systolic blood } \\
\quad \text { pressure } \\
\end{array}$ & 0.67 & - \\
\hline PROTECT $^{39}$ & 2012 & $\begin{array}{l}\text { Death, heart failure } \\
\text { rehospitalization, } \\
\text { or WHF through } \\
\text { day } 7\end{array}$ & $\begin{array}{l}\text { Higher blood urea } \\
\text { nitrogen } \\
\text { Lower serum } \\
\text { albumin } \\
\text { Lower serum } \\
\text { cholesterol } \\
\text { Lower systolic blood } \\
\text { pressure } \\
\text { Higher heart rate } \\
\text { Higher respiratory } \\
\text { rate }\end{array}$ & 0.67 & VERITAS (0.67) \\
\hline ADHERE $^{40}$ & 2015 & In-hospital WHF & $\begin{array}{l}\text { Age } \\
\text { Heart rate } \\
\text { Systolic blood } \\
\text { pressure } \\
\text { Left ventricular } \\
\quad \text { ejection fraction } \\
\text { Brain natriuretic } \\
\text { peptide } \\
\text { Troponin (positive or } \\
\quad \text { negative) } \\
\text { Sodium } \\
\text { Blood urea nitrogen } \\
\text { Creatinine }\end{array}$ & 0.74 & ASCEND (0.63) \\
\hline
\end{tabular}

Abbreviation: WHF, worsening heart failure. 
with chronic heart failure (see Fig. 1). The reasons for this remain incompletely understood, but therapeutics and treatment strategies are focused on restoring the clinical status of the patient, that is, relieving symptoms and improving congestion and perfusion. In-hospital worsening heart failure represents a failure of initial treatment strategies to achieve all of these clinical goals and is characterized by increased level of care, either medical therapy or mechanical circulatory support. Although clinical judgment is necessary for changing a level of care, this clearly documented and measurable event is representative of the many facets of the heart failure syndrome and incorporates resource utilization, an often overlooked aspect of clinical care.

The authors believe that worsening heart failure may have advantages over other acute heart failure endpoints, such as dyspnea. There are challenges with standardizing dyspnea measurements, and furthermore, although dyspnea is a patientcentered outcome, it only represents one aspect of the acute heart failure syndrome. ${ }^{34}$ As worsening heart failure continues to be incorporated into clinical trials, we must recognize that a standardized definition is required to compare results across trials. ${ }^{18,22}$ Given the continued emphasis on pragmatic clinical trials, this standardized definition of worsening heart failure should be simple and easily ascertained from electronic health records. ${ }^{35}$

\section{SUMMARY}

In-hospital worsening heart failure occurs when a patient hospitalized for treatment of acute heart failure experiences a worsening of their condition while in the hospital, requiring escalation of therapy. In-hospital worsening heart failure is associated with a worse prognosis, including worse in-hospital outcomes, increased short- and longterm postdischarge mortality, increased readmissions, and greater health care spending. Renal dysfunction, cardiac injury, and markers of decompensation are the strongest predictors of worsening heart failure. No drugs have been approved by the FDA for the prevention of worsening heart failure, but trials are ongoing. In acute heart failure trials, worsening heart failure has advantages over other endpoints commonly used in acute and chronic heart failure trials, such as dyspnea relief and mortality or rehospitalization, and should continue to be used as an endpoint in these trials. We must continue to test and evaluate treatment strategies and therapeutics for acute heart failure and we believe there is substantial evidence to support worsening heart failure as a trial endpoint in these clinical trials.

\section{REFERENCES}

1. Mozaffarian D, Benjamin EJ, Go AS, et al. Heart disease and stroke statistics-2015 update: a report from the American Heart Association. Circulation 2015;131(4):e29-322.

2. Ramirez A, Abelmann WH. Cardiac decompensation. N Engl J Med 1974;290(9):499-501.

3. Yancy CW, Jessup M, Bozkurt B, etal. 2013 ACCF/AHA guideline for the management of heart failure: a report of the American College of Cardiology Foundation/ American Heart Association Task Force on practice guidelines. Circulation 2013;128(16):e240-327.

4. Solomon SD, Dobson J, Pocock S, et al. Influence of nonfatal hospitalization for heart failure on subsequent mortality in patients with chronic heart failure. Circulation 2007;116(13):1482-7.

5. Setoguchi S, Stevenson LW, Schneeweiss S. Repeated hospitalizations predict mortality in the community population with heart failure. Am Heart J 2007;154(2):260-6.

6. Cooper LB, Hammill BG, Sharma PP, et al. Differences in health care utilization and outcomes based on timing of in-hospital worsening heart failure. Circ Cardiovasc Qual Outcomes 2015;8(Suppl 2):A324.

7. Kelly JP, Mentz RJ, Hasselblad V, et al. Worsening heart failure during hospitalization for acute heart failure: insights from the Acute Study of Clinical Effectiveness of Nesiritide in Decompensated Heart Failure (ASCEND-HF). American Heart Journal, in press.

8. Cotter G, Kaluski E, Stangl K, et al. The hemodynamic and neurohormonal effects of low doses of tezosentan (an endothelin A/B receptor antagonist) in patients with acute heart failure. Eur $J$ Heart Fail 2004;6(5):601-9.

9. Weatherley BD, Milo-Cotter O, Felker GM, et al. Early worsening heart failure in patients admitted with acute heart failure-a new outcome measure associated with long-term prognosis? Fundam Clin Pharmacol 2009;23(5):633-9.

10. Torre-Amione G, Milo-Cotter O, Kaluski E, et al. Early worsening heart failure in patients admitted for acute heart failure: time course, hemodynamic predictors, and outcome. J Card Fail 2009;15(8):639-44.

11. Teerlink JR, McMurray JJ, Bourge RC, et al. Tezosentan in patients with acute heart failure: design of the Value of Endothelin Receptor Inhibition with Tezosentan in Acute heart failure Study (VERITAS). Am Heart J 2005; 150(1):46-53.

12. McMurray JJ, Teerlink JR, Cotter G, et al. Effects of tezosentan on symptoms and clinical outcomes in patients with acute heart failure: the VERITAS randomized controlled trials. JAMA 2007;298(17): 2009-19.

13. Massie BM, O'Connor CM, Metra M, et al. Rolofylline, an adenosine A1-receptor antagonist, in acute heart failure. N Engl J Med 2010;363(15):1419-28. 
14. Hernandez AF, O'Connor CM, Starling RC, et al. Rationale and design of the acute study of clinical effectiveness of nesiritide in decompensated heart failure trial (ASCEND-HF). Am Heart J 2009;157(2): 271-7.

15. O'Connor CM, Starling RC, Hernandez AF, et al. Effect of nesiritide in patients with acute decompensated heart failure. N Engl J Med 2011;365(1):32-43.

16. Felker GM, Lee KL, Bull DA, et al. Diuretic strategies in patients with acute decompensated heart failure. N Engl J Med 2011;364(9):797-805.

17. Packer M, Colucci W, Fisher L, et al. Effect of levosimendan on the short-term clinical course of patients with acutely decompensated heart failure. JACC Heart Fail 2013;1(2):103-11.

18. Ponikowski P, Metra M, Teerlink JR, et al. Design of the RELAXin in acute heart failure study. Am Heart J 2012;163(2):149-55.e1.

19. Teerlink JR, Cotter G, Davison BA, et al. Serelaxin, recombinant human relaxin-2, for treatment of acute heart failure (RELAX-AHF): a randomised, placebocontrolled trial. Lancet 2013;381(9860):29-39.

20. Chen HH, Anstrom KJ, Givertz MM, et al. Low-dose dopamine or low-dose nesiritide in acute heart failure with renal dysfunction: the ROSE acute heart failure randomized trial. JAMA 2013;310(23):2533-43.

21. Felker GM, Butler J, Collins SP, et al. Heart failure therapeutics on the basis of a biased ligand of the angiotensin-2 type 1 receptor. Rationale and design of the BLAST-AHF study (Biased Ligand of the Angiotensin Receptor Study in Acute Heart Failure). JACC Heart Fail 2015;3(3):193-201.

22. Anker SD, Ponikowski P, Mitrovic V, et al. Ularitide for the treatment of acute decompensated heart failure: from preclinical to clinical studies. Eur Heart J 2015; 36(12):715-23.

23. European Medicines Agency. Guideline on clinical investigation of medicinal products for the treatment of acute heart failure. London: 2015.

24. FDA. FDA Briefing Document, Cardiovascular and Renal Drugs Advisory Committee Meeting. March 27, 2014.

25. Cotter G, Dittrich HC, Davison Weatherley B, et al. The PROTECT Pilot Study: a Randomized, Placebo-Controlled, Dose-Finding Study of the Adenosine A1 Receptor Antagonist Rolofylline in Patients With Acute Heart Failure and Renal Impairment. J Card Fail 2008;14(8):631-40.

26. Cotter G, Metra M, Davison BA, et al. Worsening heart failure, a critical event during hospital admission for acute heart failure: results from the VERITAS study. Eur J Heart Fail 2014;16(12):1362-71.

27. Metra M, O'Connor CM, Davison BA, et al. Early dyspnoea relief in acute heart failure: prevalence, association with mortality, and effect of rolofylline in the PROTECT Study. Eur Heart J 2011;32(12): 1519-34.
28. Metra M, Teerlink JR, Felker GM, et al. Dyspnoea and worsening heart failure in patients with acute heart failure: results from the Pre-RELAX-AHF study. Eur J Heart Fail 2010;12(10):1130-9.

29. Davison BA, Metra M, Cotter G, et al. Worsening Heart Failure Following Admission for Acute Heart Failure: a Pooled Analysis of the PROTECT and RELAX-AHF Studies. JACC Heart Fail 2015;3(5):395-403.

30. Mentz RJ, Metra M, Cotter G, et al. Early vs. late worsening heart failure during acute heart failure hospitalization: insights from the PROTECT trial. Eur J Heart Fail 2015;17(7):697-706.

31. DeVore AD, Hammill BG, Sharma PP, et al. In-hospital worsening heart failure and associations with mortality, readmission, and healthcare utilization. J Am Heart Assoc 2014;3(4):e001088.

32. Allen LA, Hernandez AF, O'Connor CM, et al. End points for clinical trials in acute heart failure syndromes. J Am Coll Cardiol 2009;53(24):2248-58.

33. Felker GM, Pang PS, Adams KF, et al. Clinical trials of pharmacological therapies in acute heart failure syndromes: lessons learned and directions forward. Circ Heart Fail 2010;3(2):314-25.

34. Gheorghiade M, Adams KF, Cleland JG, et al. Phase III clinical trial end points in acute heart failure syndromes: a virtual roundtable with the Acute Heart Failure Syndromes International Working Group. Am Heart J 2009;157(6):957-70.

35. Butler J, Fonarow GC, O'Connor C, et al. Improving cardiovascular clinical trials conduct in the United States: recommendation from clinicians, researchers, sponsors, and regulators. Am Heart J 2015;169(3):305-14.

36. Teerlink JR, Metra M, Felker GM, et al. Relaxin for the treatment of patients with acute heart failure (PreRELAX-AHF): a multicentre, randomised, placebocontrolled, parallel-group, dose-finding phase IIb study. Lancet 2009;373(9673):1429-39.

37. Cotter G, Metra M, Weatherley BD, et al. Physiciandetermined worsening heart failure: a novel definition for early worsening heart failure in patients hospitalized for acute heart failure-association with signs and symptoms, hospitalization duration, and 60-day outcomes. Cardiology 2010;115(1):29-36.

38. Metra M, Cotter G, Davison BA, et al. Effect of serelaxin on cardiac, renal, and hepatic biomarkers in the Relaxin in Acute Heart Failure (RELAX-AHF) development program: correlation with outcomes. J Am Coll Cardiol 2013;61(2):196-206.

39. O'Connor CM, Mentz RJ, Cotter G, et al. The PROTECT in-hospital risk model: 7-day outcome in patients hospitalized with acute heart failure and renal dysfunction. Eur J Heart Fail 2012;14(6):605-12.

40. DeVore AD, Greiner MA, Sharma PP, et al. The ADHERE Risk Model for in-hospital worsening heart failure. Circ Cardiovasc Qual Outcomes 2015; 8(Suppl 2):A168. 